\title{
Utmaningen med utmaningsdriven utbildning
}

\author{
Erik Falk \\ Södertörns högskola
}

\begin{abstract}
Utbildningsprogram, kurser eller kursmoment där studenter arbetar med utmaningar, ofta formulerade av samarbetsparter utanför akademin - vilka ibland benämns "challenge-based learning" - kan bidra till relevans och verklighetsanknytning i undervisning samt främja generella förmågor som samarbete, kommunikationsförmåga och kritiskt och analytiskt tänkande. Men utbildningsformen skapar också en rad problem kring undervisningsadministration, examinationsformer och organisation eftersom den bryter mot etablerade arbetssätt och traditioner inom universitetsväsendet. Den här texten beskriver och reflekterar över praktiska och pedagogiska erfarenheter från Södertörns högskola $\mathrm{i}$ arbetet med att etablera en lärosätesgemensam utmaningsbaserad kurs tillsammans med Karolinska Institutet och med samverkansparterna Huddinge och Botkyrka kommuner.
\end{abstract}

Nyckelord: samverkan, utmaningsdriven utbildning, challenge-based learning, challengedriven education, utbildningskvalitet, värde i högre utbildning

\section{INTRODUKTION}

Det finns idag i Sverige ett antal utbildningsprogram och kurser inom högre utbildning där studenter arbetar med utmaningar, ofta formulerade av eller tillsammans med icke-akademiska samarbetsparter. Utmaningarna kan spänna från stora globala till mer specifika eller lokala problem; gemensamt för dessa utbildningar är att problemen är verkliga och komplexa, är beroende av flera perspektiv och ämneskompetenser och innehåller moment där studenter gestaltar lösningar. Kohn Rådberg, Lundqvist, Malmqvist och Hagvall Svensson (20I8, s. I) definierar "challenge-based learning" på följande vis:

Challenge-based learning takes place through the identification, analysis and design of a solution to a sociotechnical problem. The learning experience is typically multidisciplinary, involves different stakeholder perspectives, and aims to find a collaboratively developed solution, which is environmentally, socially and economically sustainable.

Chalmers tekniska högskola har sedan 2014 "Challenge Lab": en "arena" där masterstudenter kan läsa utmaningsbaserade kurser eller göra sitt examensarbete i form av ämnesövergripande samarbete; Handelshögskolan i Stockholm inkluderar från 2017 ett "spår", bestående av två terminers studier, inom kandidatprogrammet Business and economics som fått namnet "Global challenges"; fyra lärosäten i Stockholmsområdet - Karolinska Institutet, Stockholms universitet, Kungliga tekniska högskolan och Södertörns högskola - samarbetar med regionala parter som Stockholms stad och landstinget i Stockholm, i masterkursen "Challenges for the emerging city" som ges inom ramen för OpenLab, beläget på KTH:s campus; KTH har sedan ett par år en "Global development hub" som syftar till att samla och utveckla utbildnings- och innovationsverksamhet med ett antal länder i Afrika kring lokalt formulerade utmaningar.

*Författarkontakt: erik.falk@sh.se

Artiklar och reflektioner är kollegialt granskade. Övriga bidragstyper granskas av redaktionen. Se https://hogreutbildning.se ISSN 2000-7558

(C)2019 Erik Falk. This is an Open Access article distributed under the terms of the Creative Commons Attribution-NonCommercial 4.0 International License (https://creativecommons.org/licenses/by-nc/4.0/), allowing third parties to share their work (copy, distribute, transmit) and to adapt it, under the condition that the authors are given credit, that the work is not used for commercial purposes, and that in the event of reuse or distribution, the terms of this license are made clear.

Citation: Erik Falk (2019) «Utmaningen med utmaningsdriven utbildning», Högre utbildning, 9(1), 38-47. http://dx.doi.org/10.23865/hu.v9.1060 


\section{DRIVKRAFTER BAKOM UTMANINGSDRIVEN UTBILDNING}

Inrättandet av de här utbildningsverksamheterna har alla givetvis sina specifika, lokala orsaker och sin enskilda bakomliggande historia, men bakgrunden till denna pågående utveckling är också både nationell och internationell. Ett par av utbildningarna hämtar direkt inspiration från internationella förebilder: OpenLab, till exempel, lutar sig i både upplägg och pedagogik mot Stanfords designskola, d-school (dschool.stanford.edu); och Handelshögskolans "Global Challenges"-spår tycks vara ett direkt svar på den amerikanska rapport, publicerad av Carnegiestiftelsen, som förordade genomgripande förändringar av de amerikanska ekonomiutbildningarna (Colby, Ehrlich, Sullivan, Dolle \& Schulman, 20II). Lärosäten som just Stanfords d-school (vilken nu också etablerar sig runtom i världen), Alvar Aalto-universitetet i Espoo, Olin College of Engineering i Massachussetts och Londons Imperial Colleges Energy Futures Lab, är bara några exempel på trendens internationella utbredning (Mulgan, Townsley \& Price, 20I6).

Schematiskt uttryckt kan utvecklingen av den här formen i Sverige sägas ske mot bakgrund av åtminstone fem sammanflätade drivkrafter som inte på något sätt är unika.

Den första är det övergripande påbudet från regering och riksdag om samverkan mellan högskola och omgivande samhälle. Universitet och lärosäten har sedan 1992 lagstadgad skyldighet att samverka med omvärlden utanför akademin (Högskolelag 1992:I434). Under de senaste åren har ett antal uppdrag och direktiv signalerat en vilja att stärka denna samverkan. 2014 gav regeringen forsknings- och innovationsfinansiärerna Vetenskapliga rådet och innovationsmyndigheten Vinnova i uppdrag att ta fram förslag på finansiering av lärosätenas verksamhet som inkluderade samverkan, och 2017 tilldelades Pam Fredman uppgiften att utreda medelstilldelningssystemet - även här med samverkan som viktig del (Styr- och resursutredningen, 2019). Den senaste forskningspropositionen betonade också starkare än tidigare att kunskapsutveckling inom högre utbildning och forskning bör ske tillsammans med aktörer utanför den akademiska världen, och framhävde de nationella och globala samhällsutmaningarna som viktiga utgångspunkter för sådan samverkan (Utbildningsdepartementet, Kunskap i samverkan, 2016, ss. 26-27, 85-92). Inom forskningsområdet omsätts dessa direkt i skapandet av strategiska samverkansprogram och utlysningar från finansiärer kring samverkansforskning.

Förväntan från aktörer i lärosätenas omgivning, såsom regioner, kommuner och näringsliv, utgör en andra viktig drivkraft. Denna påverkar, som Mats Benner visat, i högre grad de mindre och nyare universiteten och högskolorna vilka i både ord och handling anpassar sig till sin närmaste omvärld - framförallt regionen - men omfattar idag alla universitet (Benner \& Sörlin, 20I5, s. 30; se också Bjursell, Dobers \& Ramsten, 2016, s. 25).

En tredje drivkraft med mer direkt bäring på utvecklingen av utmaningsdrivna utbildningar utgörs av framgången hos pedagogiska idéer kring entreprenörskap, samhällspåverkan och medborgerlig bildning inom såväl lägre som högre utbildning. Dessa, som drivs av olika grupperingar och med ibland vitt skilda mål, har som gemensam utgångspunkt att utbildning också skapar värde för aktörer i det omgivande samhället. EU-kommissionen beskriver entreprenörskap som en nyckelkompetens och entreprenörskapsutbildning som centralt för att "rusta människor att bli ansvarstagande, företagsamma individer som har de förmågor och kunskaper som krävs för att uppnå de mål de sätter för sig själva för att leva ett meningsfullt liv" (EU-kommissionen, 20I5, s. 3, min översättning) och Sverige har sedan 2009 genom Skolverket gjort entreprenörskap till en obligatorisk del av utbildningen på gymnasiet (Skolverket, 2015, s. 13). Om entreprenörskap ursprungligen präglats - och till del fortfarande präglas - av en ekonomisk logik i vilken tillväxt och jobbskapande är målen med utbildning (något som, paradoxalt nog, är tydligt i den utvärdering av entreprenörskapsutbildning som refererats ovan) har 
begreppets innebörd både kritiserats och ändrats över tid (EU-kommissionen, 20I5; Rae, 20IO; Skolverket, 20I5, s. 7-8) och på svensk botten används ofta begreppet entreprenöriellt lärande vilket omfattar förmågor som kreativitet, samarbetsförmåga och samhälleligt engagemang (EU-kommissionen, 20I5; Hoppe, Westerberg \& Leffler, 20I7; Lackéus, Lundqvist, Williams Middleton, 2016; se också Bridge, 2015, 2017). Denna bredare bestämning av entreprenörskap kan inkludera socialt entreprenörskap och hamnar nära den anglosaxiska traditionen med service learning där bidrag till positiv förändring i lokalsamhället är en central komponent och viktigt mål i utbildning (Felten \& Clayton, 20II) och education for sustainable development som betonar bland annat problemlösning och samarbetsförmåga med utgångspunkt i världens högst verkliga och akuta klimatfrågor (se t.ex. Leicht, Heiss \& Byun, 20I8).

Tätt sammankopplad med framväxten av entreprenörskap och besläktade idéer är utvecklingen av pedagogiker och didaktiska praktiker som utgår ifrån såväl demokratiseringen av högre utbildning som den pågående teknikutvecklingen. Utmaningsdriven utbildning uppvisar släktskap med problembaserat lärande, använder sig ofta av designmetodiker, "flipped classroom"-didaktik och informations- och kommunikationsteknologi (IKT). Just utnyttjandet av IKT, menar Geoff Mulgan, Oscar Townsley och Adam Price (2016), verksamma vid den brittiska innovationsstiftelsen NESTA, är utmärkande för utmaningsdriven utbildning och bidrar till att tvinga fram nya examinationsformer.

Sist men inte minst spelar både universitetsledningars och enskilda lärares övertygelse en viktig roll i etablerandet av utmaningsdrivna utbildningar. I KTH:s "Guide to challenge-driven education" beskrivs syftet med utbildningsformen som att den ska ta vara på ambitiösa studenters vilja att förändra världen till det bättre och ge dem redskap att ta sig an samhällsutmaningar. Samtidigt betonar man att studenterna blir mer attraktiva på en arbetsmarknad där samarbetsoch problemlösningsförmåga värderas högt. Inte minst gäller det bland de "framtida beslutsfattare" som utbildningarna (och lärosätet) tänks locka till sig (Magnell \& Högfeldt, 20I5). Chalmers Challenge Lab formulerar sitt syfte i otvetydigt sociala och planetära termer: studenterna blir "förändringsagenter" i arbetet för en hållbar och god livsmiljö för hela mänskligheten (www.challengelab.org). I OpenLabs presentation står samtida och framtida samhällsutmaningar och deras lösningar i fokus, liksom studenternas förmåga att bli duktiga problemlösare med tillgång till pedagogiska redskap och flera perspektiv (www.openlabsthlm.se). Handelshögskolans "Global Challenges"-spår, slutligen, inrättades eftersom högskolan utbildar Sveriges framtida beslutsfattare och, enligt högskolans rektor Lars Strannegård, vill att deras utbildning "står i samklang med en omvärld som ständigt förändras ... Utmärkta fackkunskaper räcker inte för att bli en ledare som för samhället framåt; våra studenter måste också vara bildade och ha djup förståelse för kulturella sammanhang när de lämnar skolan” (Handelshögskolan, 20ı6).

\section{KVALITET OCH VÄRDE I UTMANINGSDRIVEN UTBILDNING}

Den kraftiga tillväxten av utmaningsbaserade utbildningar och de förhoppningar och anspråk som knyts till dem gör det naturligt att fråga på vilket sätt formen bidrar till, eller stärker, kvaliteten i utbildningen. Det är ingen enkel fråga att besvara. Kvalitet i högskoleutbildning är ett komplext och relativt begrepp, vilket inte minst det nuvarande utvärderingssystemet visar (Universitetskanslersämbetet, 20I7). Högskoleutredningens betänkande 1992 redovisade denna komplexitet med önskvärd tydlighet: kvalitet, skrev man, kan syfta på "studenternas kunskapsnivå, på utbildningens värde på arbetsmarknaden, på lärarnas kompetens, på utbildningsprocessens kvalitet, på förkunskaperna, på den sociala rekryteringen, på den geografiska spridningen av utbildningsinstitutionerna etc" (Högskoleutredningen, 1992a, s. 157). Att denna komplexitet 
leder till en cirkulär logik i kvalitetsarbetet visar till exempel rapporten Vägen till samverkanssäkrad utbildning (Ahlgren-Moritz, Alm, Christersson, Eikelboom Sällström, Esbjörnsson, Jacobsson ... Värbrand, 2016). Rapporten betonar att utbildningsprogram kan behöva omformas med avseende på till exempel lärandemål och examinationsformer för att ge plats åt samverkansinslag som bidrar till kvalitet i utbildningen. Med denna logik försvåras möjligheten att göra enkla kvalitetsjämförelser mellan utbildningar eftersom såväl kvalitetsmål som beläggen för kvalitetsuppfyllelse (som t.ex. lärandemål och mätning av genomströmningsgrad) inte går att generalisera. En parallell kan dras här med service learning-utbildningar där utbildningsmål, och därmed påföljande utvärderingsinsatser, kan handla om - och kartlägga - inte bara ämneskunskaper utan också studentens egen förändring och lärande med avseende på exempelvis bidrag till lokalsamhället och samhällsengagemang (Harrop-Allin, 20I7). Några större utvärderingar av utmaningsdriven utbildning har, mig veterligen, inte gjorts (jfr Larsson \& Holmberg, 20I8), men den uppföljning av Chalmers Challenge Lab som utförts relativt nyligen bör ses mot den här bakgrunden. I en vetenskapligt publicerad artikel beskrivs utbildningens kvalitet i termer av vad artikelförfattarna, med begrepp hämtade från FN:s globala hållbarhetsmål och det så kallade Parisavtalet, benämner "transformativt och integrativt värde". Detta inkluderar värde för samarbetsparter och intressenter - som till exempel förändrat perspektiv hos en forskargrupp, eller en omläggning av regional hållbarhetsstrategi hos samhällsplanerare - men omfattar också studenternas upplevelse av ökad självkännedom och relevans i utbildningen genom samarbete och arbete med verkliga case (Larsson \& Holmberg, 20I8).

\section{EXEMPLET SÖDERTÖRNS HÖGSKOLA}

I det svenska utbildningssystemet, som är uppbyggt kring discipliner, professioner och ämnen, där lärosätens organisationer regelmässigt speglar denna uppdelning och studentens väg ofta handlar om fördjupning och specialisering, ställs utmaningsbaserade utbildningar inför en rad både praktiska och teoretiska problem. Eftersom utbildningsformen är attraktiv, uppvisar stor potential och vissa positiva resultat finns det anledning att reflektera över dessa. Jag redovisar i det följande erfarenheter från inrättandet av en kandidatkurs på Södertörns högskola och Karolinska Institutet i samverkan med Huddinge och Botkyrka kommuner. Mer specifikt beskriver jag hur några sammanhängande svårigheter som rör ämne/område, lärande, lärandemål samt organisation och administration bemöttes på Södertörns högskola och hur de involverade i arbetet försökte lösa dessa.

Först en kort bakgrund till inrättandet av kursen. På Södertörns högskola genomfördes 20I52016 ett projekt med titeln "Utmaningsdriven samverkan" som var en del av Tillväxtverkets program "Entreprenöriell kultur på lärosäten". I projektet samarbetade ett ämne per institution (SH har fyra institutioner) med en extern part och lät studenter arbeta med behov och utmaningar formulerade av parterna. Till exempel inventerade och analyserade magisterstudenter inom konstvetenskapsämnet den offentliga konsten i Huddinge och Botkyrka kommuner och journalistikstudenter på kandidatnivå samarbetade med lokaltidningen Södra sidan inom medborgar- och datajournalistik. Totalt deltog runt 35 studenter och 6 lärare i projektet i olika omfattning. Som helhet var projektet lyckat även om det var småskaligt. Några av de värden projektet kunde dokumentera var att a) studenterna upplevde att deras utbildning fick ökad relevans och att de förbereddes för livet efter studierna; b) samverkansparterna kom åt ny kunskap och fick användning för studenternas resultat; c) en av lärarna fick deltidsanställning hos en av parterna och d) lärarna hittade nya arbetsformer - som i ett fall ledde till framtagning av ett nytt magisterprogram i konstvetenskap. 
Ett viktigt resultat av projektet var etablerandet av en ny kurs, i samarbete med tre utbildningsprogram på Karolinska Institutet (KI) (Sjuksköterske-, Arbetsterapi- och Psykologiprogrammet) och två av samverkansparterna: Huddinge och Botkyrka kommuner. Kursen betraktades å ena sidan som en intressant förlängning av projektet eftersom den använde sig av delvis samma omvärldsaktörer, å andra sidan som ett nytt steg genom en tydligt ämnes- och institutionsövergripande karaktär. Det var framförallt tre aspekter som togs med i planerings- och etableringsarbetet. Där "Utmaningsdriven samverkan" hade strukturerats som ett projekt i vilket ämnen arbetade sida vid sida med en eller ett par samarbetsparter skulle "Challenge-driven innovation with design thinking", som den nya kursen kallades på $\mathrm{SH}^{\mathrm{1}}$, vara tydligt tvärvetenskaplig och baserad på studentarbete i grupp. För att få bredd på studenternas kompetenser skulle den nya kursen delas mellan två lärosäten i Flemingsberg, med möjlighet att inkludera fler av de läroinstitutioner som finns i närområdet framöver. Kursen skulle också ta sig an problemet med personberoende som gör nya initiativ sårbara och hitta en långsiktigt hållbar modell för undervisningen. Till sist skulle kursen bidra till att skapa ömsesidig förståelse mellan de inblandade parterna givet att pilotomgången visat goda resultat - ett mål som hade eget värde eftersom kommunerna är naturliga och viktiga samarbetsparter inom såväl andra utbildningsprogram som forskningsprojekt. Dessutom, vilket var ett välkommet tillägg, skulle kursen vara på engelska för att bidra till internationaliseringen på $\mathrm{SH}$.

Inrättandet av kursen blev inte bara ett pilotprojekt i samarbetet mellan lärosäten i Flemingsberg och näraliggande parter. Det blev också något av ett pilotprojekt på högskolan. Idén växte fram i samtal mellan projektledare (undertecknad) och en lärare i medieteknik som engagerats för just detta. Istället för att komma direkt ur kollegiet - och vara en fråga för kollegiet endast kopplade arbetet samman kollegium och förvaltning i internt samarbete. Därtill utverkades en utvecklingsbudget från högskolans ledning. Förberedelserna för kursen, som bestämdes till 7,5 poäng på kandidatnivå med behörighetskrav på $60 \mathrm{hp}$, tog ett år och kursstarten flyttades fram från HTi6 till VTı7. Ett av skälen till förseningen var arbetet med kursplanen, som fick revideras fler gånger än planerat. Diskussionerna rörde framförallt nivå, behörighetskrav, teoretisk förankring och områdestillhörighet.

De ganska snåriga diskussionerna kring kursplanen var delvis förutsedda. Den planerade kursen skulle använda ämneskompetens som bas men låta studenten omsätta den i tvärvetenskapligt arbete. Kursen var inte del av någon ämnesprogression men krävde vissa förkunskaper och borde därför ligga på kandidatnivå, med behörighetskrav på $60 \mathrm{hp}$. Detta verkade gå på tvärs mot ett utbildningssystem och en lärosätesorganisation som byggt identiteter och enheter kring specifika ämnen och progression definierat som fördjupning av ett ämne och inte sällan inriktning mot forskning. På kandidatnivå krävs koppling till relevant teoribildning. Vilken var denna teoribildning, givet det tvärvetenskapliga upplägget? Kurslitteraturen skulle bestå av ett par akademiska titlar som behandlade design thinking - den didaktiska metod som skulle användas på kursen - och gav ingen större teoretisk förankring. Lösningen på problemet hämtade vi från rapporten Vägen till samverkanssäkrad utbildning (Ahlgren-Moritz m.fl., 20I6) där författarna pekar på vikten av att låta samverkansformer, lärandemål, utvärdering och uppföljning foga i varandra, och göra det utifrån ett kvalitetsperspektiv på undervisningen. Vissa lärandemål, menar de, måste kanske omformuleras, och undervisningsformer omprövas, för att

1 På KI gick den under namnet "Interdisciplinary and user-centred problem solving with design thinking" - en namnolikhet som visar att skillnaden mellan "problembaserad" och "utmaningsdriven" utbildning ibland är noll. 
kunna införa den samverkan som gör utbildningen bättre. I vårt fall ledde denna insikt till att vi införde ett lärandemål kring reflektion och kommunikation som studenten dokumenterar i en skriftlig rapport.

Arbetet med kursplanen satte också områdestillhörigheten i blixtbelysning. Varje högskolekurs tilldelas ett utbildningsområde. Utbildningsområdena är i sin tur indelade i ersättningsområden som är kopplade till statens fördelning av resurser genom de så kallade "prislapparna" i regleringsbrevet, som redovisas av Ekonomistyrningsverket. "Prislapparna" bestämmer att en utbildning till operasångare i 2018 års siffror beräknas kosta $316747 \mathrm{kr}$ per student och år, en utbildning inom medicin $64589 \mathrm{kr}$ student/år och en utbildning inom humaniora, samhällsvetenskap och juridik 3I $844 \mathrm{kr}$ student/år. Statens medelsfördelning enligt "prislapparna" omvandlas av de flesta lärosäten till motsvarande interna "prislappar". Grunden för fördelningen, som stammar från 1993 års införande av nytt resursfördelningssystem (Universitetskanslersämbetet, 20I7) är inte helt transparent. En bärande tanke, som formulerats i den föregående Högskoleutredningens betänkande Resurser för högskolans grundutbildning (Högskoleutredningen, 1992b) är att utbildningar sker i ämnen som hör hemma inom områden med helt olika karaktär. Ämnena kräver vitt skilda undervisningsformer, utrustning och lokaler, vilket gör dem mer eller mindre kostsamma. Utredningen skriver till exempel att "ämnesstoffets karaktär är kanske den faktor som mest påverkar behovet av lärarstöd. Det är t.ex. lätt att inse att ett ämne som litteraturvetenskap kräver förhållandevis större tidsinsats av studenten än av läraren ... Alltför intensiv undervisning kan vara ett hinder för inlärningsprocessen" (ibid, s. 54-55). De underliggande antagandena kring dessa prislappar förtjänar att diskuteras - vilket också görs av det nyligen presenterade betänkandet från Styr- och resursutredningen, som betraktar dem som delvis förlegade och hinder för nyskapande och ämnesöverskridande utbildning (Styr- och resursutredningen, 2019, s. 26) - men på Södertörns högskola blev denna utbildningsfilosofiska fråga omedelbart praktisk. Vilken områdestillhörighet skulle kursen ges? Att arbeta med utmaningar tycktes på ett plan göra frågan om ämne irrelevant eftersom poängen var att angripa utmaningen ur just olika ämnesperspektiv. Samtidigt var kursen en hybrid: den skulle använda sig av tidskrävande undervisningsmetoder (t.ex. workshoppar) som var brukliga inom designeller medieutbildningar vilka betingade höga ersättningar, men å andra sidan inte använda sig av dyr utrustning som är vanligt i utbildningar med högre prislapp, såsom läkar- och ingenjörsutbildningar. Lösningsförslagen skulle visualiseras genom enkla prototyper i kartong och papper, lera eller i bildspel. ${ }^{2}$ Dessutom kom utmaningarna ur sociala eller kulturella sammanhang snarare än exempelvis tekniska. Området bestämdes slutligen till "tekniskt" trots allt eftersom det ansvariga ämnet som blev organisatorisk hemvist, medieteknik, kodat alla sina kurser så.

En betydande svårighet gällde inrättandet av en organisatorisk struktur runt kursen som borgade för långsiktighet. God samverkan vilar på mänskliga relationer och människors engagemang. Samtidigt är engagemanget ändligt och personberoendet det ofta resulterar i blir lätt en svaghet i samarbetet. I stora samverkansformer, som strategiska partnerskap, upprättas ofta styrgrupper och arbetsgrupper, men kring en kurs verkade detta orealistiskt. Organisatoriskt fanns också en risk att den nödvändiga ämnestillhörigheten - medieteknik - skulle skapa ett slags ofrivilligt ägarskap som minskade lusten för lärare från andra ämnen och institutioner att involvera

2 Förhållandet mellan ämne, didaktiska metoder och utrustning är i sig en knepig fråga: Universitetskanslersämbetet (UKÄ) $(2017: 6,28)$ betonar att det är "ämnet" som betingar ersättningsområdet och därmed prislappen, men redogör samtidigt för att ett antal lärosäten väger in aspekter som tidsåtgång och undervisningsformer när de sätter sina interna prislappar på kurser. 


\section{Erik Falk}

sig och, omvänt, att medietekniklärarna skulle betrakta kursen som en av "sina" kurser. När vi övergett idén om en styrgrupp för kursen, liksom tanken att kursen kunde rotera bland ämnen och institutioner (vilket skulle påverka legitimiteten i områdestilldelningen) beslöt vi att ordna en kringaktivitet: en workshop i den undervisningsmetod - design thinking - som kursen använde sig av. Workshoppen fick på det viset ett dubbelt syfte: att samla utmaningsgivare och kurslärare/ansvariga för att kalibrera förväntningar och dryfta frågor, och att intressera lärare/ programansvariga vid respektive lärosäte för kursen och arbetsmetoden, i hopp om att de så småningom kunde tänka sig undervisa på den.

Kursen "Challenge-driven innovation with design thinking" har i skrivande stund genomförts fyra gånger. Det är en mindre kurs med runt Is studenter varje termin, den har en större andel utländska studenter än många andra kurser på högskolan (och bidrar alltså till internationaliseringen) och uppvisar goda studenterfarenheter. Eftersom den getts ett antal gånger är det möjligt att utifrån ambitionerna summera några erfarenheter av den.

För det första fungerar kursen som en pusselbit i den övergripande samverkan med parterna: Huddinge kommun deltar till exempel nu i utvecklingen av ett masterprogram med hållbart ledarskap med planerad start HTı9. Samtidigt formuleras värdet av kursen hos samverkansparten ganska allmänt och dess medverkan kan inte tas för given. För det andra har bandet till KI inte kunnat upprätthållas och KI-studenter har medverkat endast under det första tillfället, trots avsikten från flera program att delta i kursen. För det tredje har ansvarsfördelningen breddats inom det ansvariga medieteknikämnet genom att fler lärare har blivit involverade i undervisningen, vilket gjort kursen mindre sårbar. Däremot har inga lärare utanför ämnet engagerats.

Om hållbarheten inom lärosätet alltså ser ganska god ut, lämnar 'vårdandet' av relationen i samverkan en del i övrigt att önska. Kommunernas ganska allmänt positiva inställning antyder behov av en tydligare formulering kring värdet av samverkan från deras sida och en större beredskap att ta hand om resultaten från den. Andra lärosäten (t.ex. KI) behöver återigen bjudas in om kursen ska bli den campusgemensamma aktivitet som var tanken initialt. För att parera ett eventuellt svalnande intresse från nuvarande samverkansparter skulle ytterligare potentiella parter kunna kontaktas.

Erfarenheterna från Södertörns högskola kan ganska väl sammanfattas under de två rubriker Lars Bengtsson menar är centrala i utbildningssamverkan: "organisatoriska faktorer", med vilka han menar till exempel formalisering, resurssättning och lämplig organisation, och "processfaktorer", som inbegriper sådant som projektledarskap, kommunikation och "socialt kapital", det vill säga tillit och förståelse (Bengtsson, 20I3, s. 2I-23). Högskolans organisation var inte optimalt rustad för arbetet med att inrätta utbildning på tvärvetenskaplig grund med stort inslag av samverkan och internt samarbete. Det fanns till exempel inga etablerade fora för att samla (delar av) kollegiet kring en diskussion om en dylik kurs; inte heller fanns upparbetade former för hur samarbetet med samverkansparter skulle skötas. Dessa fick uppfinnas ad hoc, liksom resurssättningen för arbetet med att ta fram kursen och driva den extra administration som kursen krävde. Försöken att upprätthålla samverkansrelationen visar också på svårigheter eftersom det finns lite tid och resurser för att diskutera fram gemensamma värden och mål. Processförhållandena var däremot gynnsamma för att inrätta kursen. Utöver möjligheten att bedriva ett ganska aktivt projektledarskap från centralt håll fanns ett stort engagemang hos en lärare med stor erfarenhet av utmaningsdriven utbildning, liksom intresse från andra delar av kollegiet. Högskolans ledning var också positivt inställd till initiativet och frigjorde extra medel som kunde användas till workshops som förde samman parter och intressenter. Likaså var kursplanehandläggarna samarbetsvilliga kring en knepig och tidskrävande uppgift. 


\section{AVSLUTANDE DISKUSSION}

Utmaningsdriven utbildning har potential att skapa relevans och kvalitet i utbildningen, inte minst genom att ta sig an de svårigheter som hela planeten står inför, och främja kunskaper som morgondagens ledare, arbetstagare och medborgare behöver. Utmaningsdriven utbildning drivs också på av statsmakterna, regionala intressenter och utvecklingen inom det pedagogiska fältet. Pågående arbete vid svenska och utländska lärosäten med att integrera FN:s globala hållbarhetsmål i såväl forskning som undervisning och framtidsspaningar om "framtidens universitet" visar också att utbildningsformen med stor sannolikhet har framtiden för sig (Davey, Meerman, Orazbayeva, Riedel, Galán-Muros, Plewa \& Eckert, 2018, ss. 23, 49, 74).

Som inrättandet av kursen "Challenge-driven innovation with design thinking" på Södertörns högskola visar ställer utmaningsdriven utbildning såväl ämnen och discipliner som universitetets organisation inför en rad pedagogiska, organisatoriska och ekonomiska hinder (eller utmaningar). Utmaningsbaserad utbildning har till exempel inte nödvändigtvis ett givet "ämne", och därmed inte heller en självklar institutionstillhörighet eller utbildningsområde. Kursplanernas utformning, lärandemål och examinationsformer skiljer sig också från de traditionella. Dessutom har utbildningar baserade på kollektivt studentarbete och tvärvetenskap ofta behov av extra administrativ draghjälp, till exempel i form av workshoppar, kontaktskapande och relationsunderhållande aktiviteter som normalt hamnar utanför undervisningsbetinget.

En del av svårigheterna kan lärosäten bara delvis råda över, till exempel den statliga medelsfördelningen enligt "prislapparna" för utbildning, men lärosäten som intresserar sig för tvärvetenskaplig, samskapande utbildning med stora inslag av samverkan gör gott i att reflektera över de "organisatoriska faktorer" och de "processfaktorer" som, med Lars Bengtssons termer, antingen underlättar eller försvårar införandet av utmaningsbaserad undervisning, vare sig det gäller mötesplatser och arbetsformer inom lärosätet där lärare kan hitta gemensamma intressen och utveckla gemensamma utbildningar, eller kanaler och samverkansaktiviteter som underlättar kontakter med samverkansparter.

\section{FÖRFATTARPRESENTATION}

Erik Falk, fil.dr, har tidigare varit lektor i engelska på Södertörns högskola liksom vid ett antal andra lärosäten i Sverige. Han är idag handläggare inom samverkan på SH, och för närvarande också knuten till Nordiska Afrikainstitutet där han forskar om östafrikansk samtida engelskspråkig litteratur inom programmet "World literatures: Cosmopolitan and Vernacular Dynamics".

\section{REFERENSER}

Ahlgren-Moritz, C., Alm, A.-K., Christersson, C., Eikelboom Sällström, A., Esbjörnsson, M., Jacobsson, A., ... Värbrand, P. (2016). Vägen till samverkanssäkrad utbildning. [1] : Metoder och strategier. Malmö, Umeå, Linköping. Åtkomst: http://urn.kb.se/resolve?urn=urn:nbn:se:liu:diva-130488

Bengtsson, L. (2013). Utbildningssamverkan - för jobb, innovation och företagande. Almega kommunikation. Benner M. \& Sörlin, S. (2015). Samverkansuppgiften i ett historiskt och institutionellt perspektiv (Vinnova rapport, VA 2015:02). Verket för innovationssystem - VINNOVA.

Bjursell, C., Dobers, P. \& Ramsten, A. (2016). Samverkansskicklighet: for personlig och organisatorisk utveckling. (1. uppl.) Stockholm: Studentlitteratur.

Bridge, S. (2015). Is enterprise education relevant to social enterprise? Education + Training, 57(8/9), 1009_ 1019. https://doi.org/10.1108/ET-05-2015-0030

Bridge, S. (2017). Is "entrepreneurship" the problem in entrepreneurship education? Education + Training, 59(7/8), 740-750. https://doi.org/10.1108/ET-02-2016-0037

Chalmers ChallengeLab. Åtkomst: www.challengelab.org. 


\section{Erik Falk}

Colby, A., Ehrlich, T., Sullivan, W. M., Dolle, J. R. \& Shulman, L. S. (2011). Rethinking undergraduate business education: Liberal learning for the profession (1st ed., Vol. 20, The Carnegie Foundation for the Advancement of Teaching;). San Francisco, CA: Jossey-Bass.

Davey, T., Meerman, A., Orazbayeva, B., Riedel, M., Galán-Muros, V., Plewa, C., Eckert, N. (red.) (2018). The Future of Universities Thoughtbook: 40 Perspectives on How Engaged and Entrepreneurial Universities Will Drive Growth and Shape Our Knowledge-Driven Future Until 2040. Amsterdam: University Industry Innovation Network.

Ekonomistyrningsverket (2018). Regleringsbrev för budgetåret avseende universitet och högskolor. https:// www.esv.se/statsliggaren/regleringsbrev/?RBID $=18909$

EU-kommissionen (2015). Entrepreneurship education: a road to success. A compilation of evidence on the impact of entrepreneurship education strategies and measures. Brussels: European Union.

Felten, P. \& Clayton, P. H. (2011). Service-learning. New Directions for Teaching and Learning, 2011(128), 75-84. https://doi.org/10.1002/tl.470

Handelshögskolan i Stockholm (2016, 2 september). Handelshögskolan i Stockholm stöper om grundutbildningen - nya spåret Global Challenges ska forma morgondagens ledare. Åtkomst: https://www.hhs. se/sv/om-oss/news/2016/handelshogskolan-i-stockholm-stoper-om-grundutbildningen---nya-sparet-global-challenges-ska-forma-morgondagens-ledare/

Harrop-Allin, S. (2017). Higher education student learning beyond the classroom: findings from a community music service learning project in rural South Africa. Music Education Research, 19(3), 231-251. https://doi.org/10.1080/14613808.2016.1214695

Hoppe, M., Westerberg, M. \& Leffler, E. (2017). Educational approaches to entrepreneurship in higher education: A view from the Swedish horizon. Education + Training, 59(7/8), 751-767. https://doi. org/10.1108/ET-12-2016-0177

Högskolelag (1992:1434). URL: https://www.riksdagen.se/sv/dokument-lagar/dokument/svensk-forfattningssamling/hogskolelag-19921434_sfs-1992-1434

Högskoleutredningen (1992a). Frihet, ansvar, kompetens: grundutbildningens villkor i högskolan: betänkande (SOU, 0375-250X; 1992:1). Stockholm: Allmänna förlaget.

Högskoleutredningen (1992b). Resurser för högskolans grundutbildning: betänkande (SOU, 0375-250X; 1992:44). Stockholm: Allmänna förlaget.

Kohn Rådberg, K., Lundqvist, U., Malmqvist, J., \& Hagvall Svensson, O. (2018). From CDIO to challenge-based learning experiences - expanding student learning as well as societal impact? European Journal of Engineering Education, 1-16. https://doi.org/10.1080/03043797.2018.1441265

Lackéus, M., Lundqvist, M. \& Williams Middleton, K. (2016). Bridging the traditional-progressive education rift through entrepreneurship. International Journal of Entrepreneurial Behavior \& Research, 22(6), 777-803. https://doi.org/10.1108/IJEBR-03-2016-0072

Larsson, J. \& Holmberg, J. (2018). Learning while creating value for sustainability transitions: The case of Challenge Lab at Chalmers University of Technology. Journal of Cleaner Production, 172, 4411-4420. https://doi.org/10.1016/j.jclepro.2017.03.072

Leicht, A., Heiss, J. \& Byun, W. J. (red.) (2018). Issues and Trends in Education for Development. Paris: UNESCO Publishing.

Magnell, M. \& Högfeldt, A-K. (2015). A guide to challenge-driven education. Stockholm: KTH. Åtkomst: https://www.kth.se/social/group/guide-to-challenge-d/

Mulgan, G., Townsley, O. \& Price, A. (2016). The challenge driven university: how real-life problems can fuel learning. Lonon: NESTA. URL: https://www.nesta.org.uk/blog/the-challenge-driven-universityhow-real-life-problems-can-fuel-learning/

OpenLab. Åtkomst: http://openlabsthlm.se/

Rae, D. (2010). Universities and enterprise education: responding to the challenges of the new era. Journal of Small Business and Enterprise Development, 17(4), 591-606. https://doi.org/10.1108/ 14626001011088741 
Recommendation of the European Parliament and of the Council of 18 December 2006 on key competences for lifelong learning. OJ L 394, 30.12.2006, 10-18. Åtkomst: http://eur-lex.europa.eu/legal-content/ $\mathrm{EN} / \mathrm{TXT} /$ ?uri=celex$\% 3 \mathrm{~A} 32006 \mathrm{H} 0962$

Regeringen, Utbildningsdepartementet (2016). Kunskap i samverkan: for sambällets utmaningar och stärkt konkurrenskraft (Prop 2016/17:50). Åtkomst: https://www.regeringen.se/rattsliga-dokument/proposition/2016/11/prop.-20161750/

Skolverket (2015). Skapa och våga: om entreprenörskap i skolan (Forskning för skolan). (Rev. uppl.) Stockholm: Skolverket.

Sverige Styr- och resursutredningen (Strut) (2019). En lingsiktig, samordnad och dialogbaserad styrning av högskolan (SOU, 0375-250X; 2019:6). Stockholm: Norstedts juridik. Åtkomst: https://data.riksdagen.se/fil/C1DAFFDF-F5F9-42C7-A88A-8E409DAF4318

Södertörns högskola. Challenge-driven Innovation with Design Thinking. Åtkomst: https://www.sh.se/program--kurser/kurser/grund/challenge-driven-innovation-with-design-thinking

Universitetskanslersämbetet (2017). Uppföljning av ersättningsbeloppen för högre utbildning. 2017:6. Stockholm: Universitetskanslersämbetet. Åtkomst: https://www.uka.se/download/18.458252e315a188bd3e75c93/1488372286077/rapport-2017-03-01-uppfoljning-ersattningsbelopp.pdf

Utbildningsdepartementet (2016, 20 december). Regleringsbrev för budgetaret 2017 avseende universitet och högskolor. Åtkomst: http://www.esv.se/statsliggaren/regleringsbrev/?RBID=17920 